DOI: https://doi.org/10.36910/6775-2524-0560-2020-41-10

УДК 004.93

Левицька Тетяна Олександрівна, к.т.н., доцент

https://orcid.org/0000-0003-3359-1313

Железов Дмитро Анатолійович, магістр

ДВНЗ «Приазовський державний технічний університет», м. Маріуполь, Україна.

\title{
МОДЕЛЮВАННЯ НЕЙРОННИХ МЕРЕЖ ДЛЯ ОЦІНКИ РИНКОВОЇ ВАРТОСТІ ОБ'ЄКТА ЖИТЛОВОЇ НЕРУХОМОСТІ
}

Левицька Т.А., Железов Д.А. Моделювання нейронних мереж для оцінки ринкової вартості об'скта житлової нерухомості. Представлено концепт системи з використання багатошарового персептрону для оцінки ринкової вартості об'єктів житлової нерухомості Виконано та обосновано відбір факторів, що впливають на ринкову вартість квартир. Проведено моделювання у середовищі Deductor Studio Academic та встановлено оптимальну архітектуру багатошарового персептрону та їі параметри.

Ключові слова: моделювання, нейронні мережі, навчання, оцінка вартості, житлова нерухомість

Левицкая Т.А., Железов Д.А. Моделированию нейронных сетей для оценки рыночной стоимости объекта жилой недвижимости. Представлен концепт системы с использованием многослойного персептрона для оценки рыночной стоимости объектов жилой недвижимости Выполнено и обосновано отбор факторов, влияющих на рыночную стоимость квартир. Проведено моделирование в среде Deductor Studio Academic и установлена оптимальная архитектура многослойного персептрона и ее параметры.

Ключевые слова: моделирование, нейронные сети, обучение, оценка стоимости, жилая недвижимость.

Levitskaya T.A., Zhelezov D.A. Modeling neural networks for assessing the market value of a residential property. The concept of a system using a multilayer perceptron for assessing the market value of residential real estate objects is presented. The selection of factors affecting the market value of apartments has been completed and substantiated. Modeling was carried out in the Deductor Studio Academic environment and the optimal architecture of the multilayer perceptron and its parameters were established.

Key words: modeling, neural networks, training, cost estimation, residential real estate.

Постановка проблеми. У грудні 2019 року Верховна Рада прийняла закон «Про внесення змін до Податкового кодексу України щодо ліквідації корупційної схеми у сфері реєстрації інформації зі звітів про оцінку об'єктів нерухомості та прозорості реалізації майна» [1]. Цим законом спрощується процедура оцінки нерухомості та запроваджується новий альтернативний спрощений спосіб оцінки об'єктів нерухомості через автоматичну ії оцінку модулем Фонду державного майна України.

У відповідності до цього закону Фонд державного майна був повинен 31 липня 2020 року забезпечити функціонування у складі Єдиної бази даних звітів про оцінку модуля електронного визначення оціночної та/або ринкової вартості, сервісу послуги електронного визначення оціночної вартості та автоматичного формування електронних довідок про оціночну вартість об'єкта нерухомості $[1,2]$.

Завдяки цій системі будь-яка особа змогла б отримати автоматичну довідку про оцінку об'єкту нерухомого майна. Розробка, тестування та введення в промислову експлуатацію такої інформаційнотелекомунікаційної системи потребує значних витрат часу та коштів, які були спочатку передбачені Фонду в Державному бюджеті на 2020 рік. Втім, через об'єктивну необхідність фінансувати більш нагальні програми щодо підтримки медичної, соціальної сфери під час пандемії коронавірусної хвороби COVID-19 та спричиненого нею карантину, ця стаття бюджетних витрат була повністю урізана Законом про внесення змін до закону "Про Державний бюджет України на 2020 рік" від 13.04.2020 № 553- IX. [3]. Тому модуля електронного визначення оціночної та/або ринкової вартості поки що не розроблено.

У зв'язку з цим актуальним є створення математичних моделей і комп'ютерних програм, що дозволять виконати ринкову оцінку об'єктів нерухомості, зокрема, міських квартир, що мають будівельні, експлуатаційні, географічні характеристики. При розробці такої системи доцільно використовувати практичний досвід експертів (оцінювачів) отже варто створювати систему 3 використанням підходів штучного інтелекту.

Оцінка нерухомості є необхідною послугою для юридичних та фізичних осіб при безлічі юридичних, нотаріальних та фінансових оформленнях та операціях [4]. Основна мета цієї послуги - це визначити ринкову (оціночну) вартість нерухомого майна. Ринкова вартість об'єкта - найбільш ймовірна ціна, по якій даний об'єкт може бути відчужений на відкритому ринку в умовах конкуренції.

В першу чергу на вартість об'єктів житлової нерухомості вказують вплив фінансовоексплуатаційні та архітектурно-будівельні чинники, які безпосередньо пов'язані 3 об'єктом нерухомості і його технічними та будівельно-експлуатаційні характеристиками [4-]: кількість кімнат, 
тип будинку, поверховість будинку, поверх розташування у будинку. загальна площа, житлова площа, площа кухні, стан.

За кількістю кімнат квартири можуть бути: 1-кімнатні, 2-кімнатні, 3-кімнатні, 4-кімнатні, багатокімнатні, студії. Тип будинку зазвичай визначають в залежності від типу матеріалів 3 яких він побудований: стіни панельні, стіни цегляні, стіни блочно-цегляні. Також під типом будинку розуміють поєднання типу планування (проекту) та періоду побудови. В цьому випадку в Маріуполі виділяють наступні типи будинків: «купецький», «сталінка», «хрущевка», «гостинки», «панельний», «чешка», «новострой».

За поверховістю будинки поділяються на: 2-поверхові, 5-поверхові, 9-поверхові, 12- поверхові, 14-поверхові. Для квартири важлива характеристика - поверх розташування. Зазвичай квартири на першому та самому верхньому поверсі стоять дешевше. Стан квартири визначається придатністю до житла: «підготовка під ремонт», «добрий», «після ремонту». Також важливим фактором $є$ просторовий чинник, що визначає порівняльні переваги об'єкту нерухомості відповідно його територіального розташування стосовно центру - тобто район. У місті Маріуполі $є 4$ району: Центральний, Приморський, Лівобережний та Кальміуський.

Для отримання достовірних результатів в процесі оцінки і прогнозування ринкової вартості нерухомості необхідно ретельно виявляти, аналізувати і враховувати всі представлені фактори. Найбільш популярним для прогнозування $є$ використання нейромережевих технологій.

Аналіз останніх досліджень та публікацій. На сьогодні вже авторами опубліковані результати дослідження проблеми з використанням нейромереж:

-для прогнозування тенденцій ринку нерухомості [6, 12];

-для проведення масової оцінки земель [7-8],

-в оцінці вартості будівельних проектів [9],

-прогнозування індикаторів ринку нерухомості [10];

-для оцінки вартості оренди об'єкта офісної нерухомості [11];

- прогнозування ринку нерухомості у кризових умовах [13].

Сучасний стан публікацій наступний. В статті [6] розглянуто сутність нейронних мереж, методи ïх проектування та навчання, переваги моделей оцінки нерухомості, побудованих на основі нейронних технологій. Теоретичні положення проілюстровано на прикладі нейронної мережі, що дає змогу здійснювати короткостроковий прогноз ціни на житлову нерухомість у Чернівцях. Для навчання дворівневого перцептрону 7-3-1 використовувався пакет Excel Neural Package компанії "НЕЙРООК", який доповнює пакет MS Excel алгоритмами оброблення даних, що використовують технології нейронних мереж.

Автори Алексєєв А.О., Харітонов В.А., Ясніцький В.Л. в своій роботі [7] пропонують концепцію комплексного нейросетевого моделювання процесів масової оцінки і сценарного прогнозування ринкової вартості об'єктів житлової нерухомості Для моделювання багатошарового перцептрону авторами був використаний пакет нейромережевого моделювання в програмному середовищі Statistica Neural Networks.

В публікації [11] наводяться результати дослідження по підбору оптимальної архітектури нейронної мережі для цілей оцінки об'єктів офісної нерухомості. Досліджено моделі нейронних мереж 3 архітектурою багатошарового персептрона (9-11-1 і 7-9-1) і мережу радіальних-базисних функцій (1260-1, 12-44-1, 12-29-1). Для моделювання мереж застосовувався пакет програмних засобів STATISTICA Neural Networks фірми StatSoft. В результаті проведених експериментів найменшу помилку показала мережа радіальних-базисних функцій з архітектурою 12-60-1.

В роботі [12] авторів Вороніна В.О., Мамчина М.М., Лянце Е.В., досліджено якість прогнозування в отриманні обгрунтованих і надійних прогнозних оцінок в розвитку об'єктів високої складності, зокрема, ринку нерухомості. Обгрунтовано доцільність використання технології нейронних мереж для аналізу і прогнозування тенденцій ринку нерухомості. Наведено алгоритм нейромережевого прогнозування і здійснено побудову прогнозної моделі з використанням програми Neurosolutions for Excel. Виділено і проаналізовано можливі сценарії подальшої поведінки показників, що характеризують розвиток об'єктів різних рівнів у прогнозному горизонті. Запропонована модель (предиктор) на основі проведених розрахунків в середньостроковому горизонті прогнозування коректно передбачила тенденцію розвитку ринку нерухомості на 2009-2011 pp.

В роботі [13] здійснено прогнозування ринку нерухомості у кризових умовах за допомогою нейромережі. Для нейромережевого прогнозування ринку нерухомості у кризових умовах створено зведену таблицю 3 даними про об'єкти нерухомості. Наведено схематичний процес навчання нейромережі. На підставі даних про об'єкти нерухомості проведено навчання нейромережі. Застосовано методи математичної статистики, засновані на сукупності певних правил для точних 
цифрових даних узагальненого характеру. Загальний прогноз за нейромережевого прогнозування ринку нерухомості у кризових умовах знайдено шляхом множення значення детермінації на кожне індивідуальне значення, отримане на основі результату нейромережевого моделювання.

В роботі [14] на основі нейромережевого підходу розроблена методика, що дозволяє виробляти визначення ринкової вартості квартир, аппробірована на базі даних міста Тула. Автори моделювали багатошаровий персептрон (MLP), мережу радіально-базисних функцій (RBF), узагальнено-регресійну нейронну мережу (GRNN). Як інструментальний засіб проектування нейронної мережі була обрана STATISTICA Neural Networks.

В рамках роботи [15] розглянуто хід побудови нейромережевої моделі оцінки ринкової вартості нерухомості з багатошаровою архітектурою (14-4-2-3-2-1) в Deductor Studio Academic.

Інши роботи [16-17] також показують, що нейронні мережі різних архітектур $\epsilon$ одним 3 найкращих засобів для аналізу багатовимірних, топологічно взаємозалежних наборів даних, якими $\epsilon$ набори факторів для оцінки житлової нерухомості. Здатність нейронних мереж знаходити сильно нелінійні залежності між вхідними факторами і вихідним значенням і виділяти 3 наборів найбільш значущі компоненти робить нейронні мережі незамінним інструментом для розв'язання задачі оцінки об'єктів житлової нерухомості [8].

Таким чином, в якості інтелектуального засобу для оцінки об'єктів житлової нерухомості доцільно використання моделей штучних нейронних мереж, а саме багатошарового персептрону.

Метою даної роботи $є$ дослідження і моделювання нейронної мережі для оцінки ринкової вартості об'єктів житлової нерухомості на прикладі м. Маріуполь.

Для досягнення зазначеної мети необхідно вирішити наступні завдання:

- попередній відбір факторів, що впливають на ринкову вартість квартир;

- підготовка навчальної вибірки для нейронної мережі;

- визначення оптимального типу та характеристик нейронної мережі.

Виклад основного матеріалу.

Найбільше оголошень про продаж квартир у м. Маріуполь було зведено на сайті «Вся нерухомість України» [15] - 348 одиниць на вересень 2020 року. Шляхом парсінгу (Parsing) за допомогою окремо розробленого додатку з цього сайту було сформовано БД з 266 унікальними записами. На основі аналізу параметрів оголошень та робіт, які досліджували вплив різних чинників на вартість нерухомості, визначено набір параметрів для формування навчальної вибірки: район, кількість кімнат, поверх, кількість поверхів в будинку, тип будинку, загальна площа, житлова площа, площа кухні, стан. На основі відмінностей в характеристиках пропонованих об'єктів встановлені наступні значення для входів нейронної мережі:

Х1 - кількість кімнат;

X2 - район: 1 - Центральний; 2 - Лівобережний; 3 - Приморський; 4 - Кальміуський;

Х3 - тип будинку, закодований наступними значеннями: 1 - панельний; 2 - «брежневка»; 3 «хрущовка»; 4 - «сталінка»; 5 - цегляний; 6 - «чешка»; 7 - «новострой»; 8 - «купецький»;

$\mathrm{X} 4$ - поверх;

$\mathrm{X} 5$ - всього поверхів у будинку;

Х6 - загальна площа (кв. м.);

X7 - житлова площа (кв. м.);

Х8 - площа кухні (кв. м.);

Х9 - стан об’єкту: «підготовка під ремонт» - 0, «добрий» - 1, «після ремонту» - 2.

Наступним етапом була підготовка навчальної вибірки, яка складалась 3 двох частин. По-перше було виконане відсікання «екстремальних» об'єктів, що мають занадто значну відмінність від середнього, тобто значно дешевих та занадто дорогих квартир. Таким чином, було відсічена приблизно $10 \%$ вибірки і залишилось у БД 240 записів. По-друге, проведено нормалізацію вхідних даних за методом мінімакса.

Масив підготовлених даних було розділено випадковим чином на наступні частини: навчальна вибірка (80\%), тестова вибірка (10\%) і контрольна вибірка (10\%).

Далі було проведено моделювання нейронної мережі безпосередньо у Deductor Studio Academic. Для встановлення наявності зав'язків між обраними факторами і вихідною величиною - ціною, було проведено кореляційний аналіз. Результат впливу входів показаний на рисунку 1. 


\begin{tabular}{|c|c|c|c|}
\hline \multicolumn{2}{|r|}{ Входные поля } & \multicolumn{2}{|c|}{ Корреляция с выходными полями } \\
\hline$N \pm$ & Поле & Цена & \\
\hline 1 & Комнат & $\square$ & 0,637 \\
\hline 2 & Район & \begin{tabular}{|c|} 
\\
\end{tabular} & $-0,305$ \\
\hline 3 & этаж & $\square$ & 0,025 \\
\hline 4 & всего этажей & $\square$ & $-0,040$ \\
\hline 5 & Общая площадь & \begin{tabular}{|l} 
\\
\end{tabular} & 0,687 \\
\hline 6 & Жилая площадь & $\square$ & 0,673 \\
\hline 7 & Кухня & ${ }^{\square}$ & 0,299 \\
\hline 8 & тип дома & $\square$ & $-0,086$ \\
\hline 9 & ремонт & \begin{tabular}{|l} 
\\
\end{tabular} & 0,269 \\
\hline
\end{tabular}

Рисунок 1 - Вплив на ціну об’єкту

Для моделювання багатошарового персептрону важливий етап - визначення його архітектури кількості прихованих шарів та кількості в них нейронів. В даний час немає жорстких правил ні для вибору кількості прихованих шарів, ні для вибору кількості нейронів в них. Деякі автори користуються формулою наслідком теорем Арнольда-Колмогорова-Хехт-Нільсена [14-15], більшість визначають це за допомогою експериментів, інтуїції, систематичного або евристичного пошуку. Для початку моделювання було обрано архітектури нейронних мереж вже описані іншими авторами по цій темі.

Після проведення серії з 38 експериментів з різними типами і формами нейронних мереж були визначені найкращі варіанти мережі за найменшою контрольної помилкою, що наведені у таблиці 1.

Таблиця 1 - Приклади результатів навчання багатошарового персептрону

\begin{tabular}{|c|l|l|l|c|}
\hline № & Архітектура & $\begin{array}{c}\text { Помилка } \\
\text { навчання }\end{array}$ & $\begin{array}{c}\text { Помилка } \\
\text { тестування }\end{array}$ & Кореляція \\
\hline 1 & $9-32-16-1$ & 0,0083 & 0,0495 & 0,994 \\
\hline 2 & $9-12-2-1$ & 0,0510 & 0,0671 & 0,901 \\
\hline 3 & $9-28-8-1$ & 0,0071 & 0,1330 & 0,928 \\
\hline
\end{tabular}

3 таблиці видно, що не завжди найменша помилка при навчанні показує кращій результат навчання. Важливим $є$ показник помилки на тестовому наборі. Найбільш вдалий результат навчання було отримано для мережі 9-32-16-1 з функцією активації - «сігмоід», алгоритм навчання «з вчителем» Resilient Propagation (RPROP), кроки спуску $=0,4$ крок підйому дорівнює 1,2 . Крок спуску - в разі зміни знаку градієнтної складової помилки для даної ваги задає величину наступної корекції ваги. Крок підйому - в разі збереження знаку градієнтної складової помилки для даного ваги задає величину наступної корекції ваги.

Приклад процесу навчання показано на рисунку 2. Діаграма розсіювання, що показана на рисунку 3 , демонструє збіг ціни початкової та прогнозованої нейронною мережею.

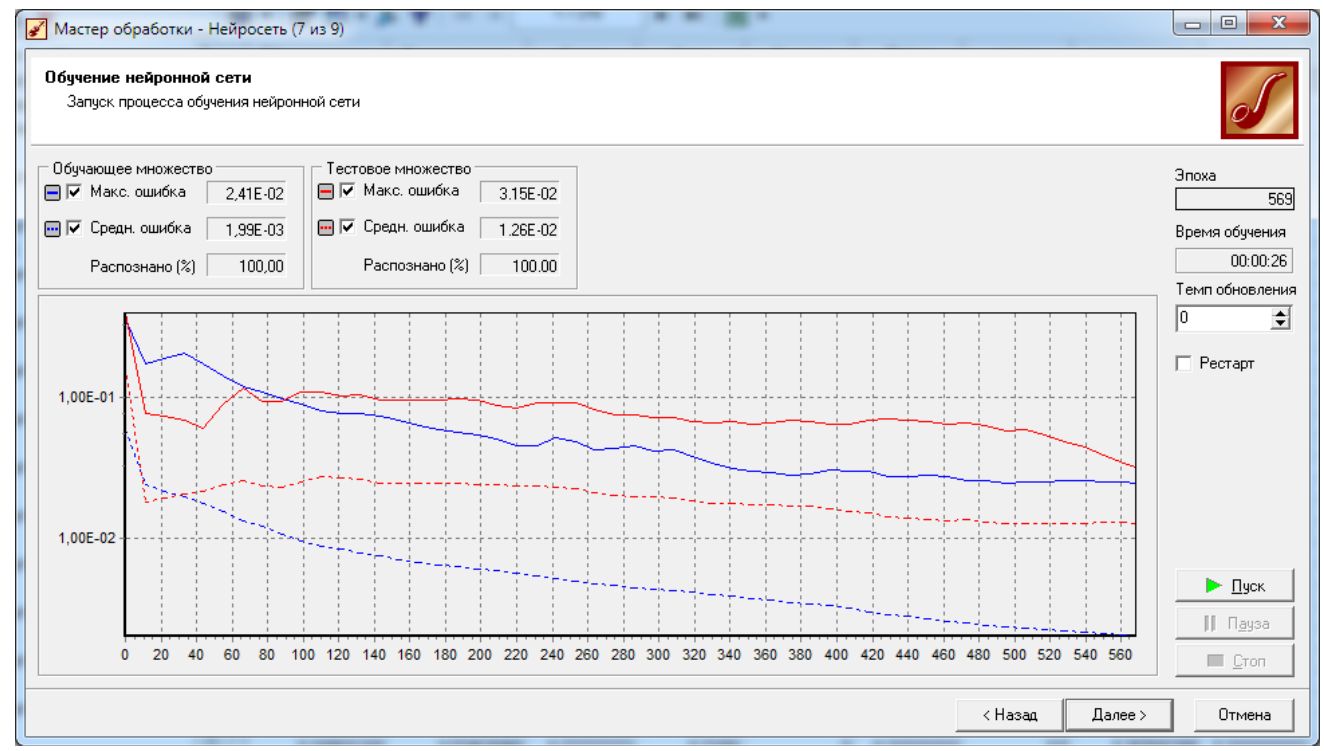

Рисунок 2 - Процес навчання нейронної мережі 


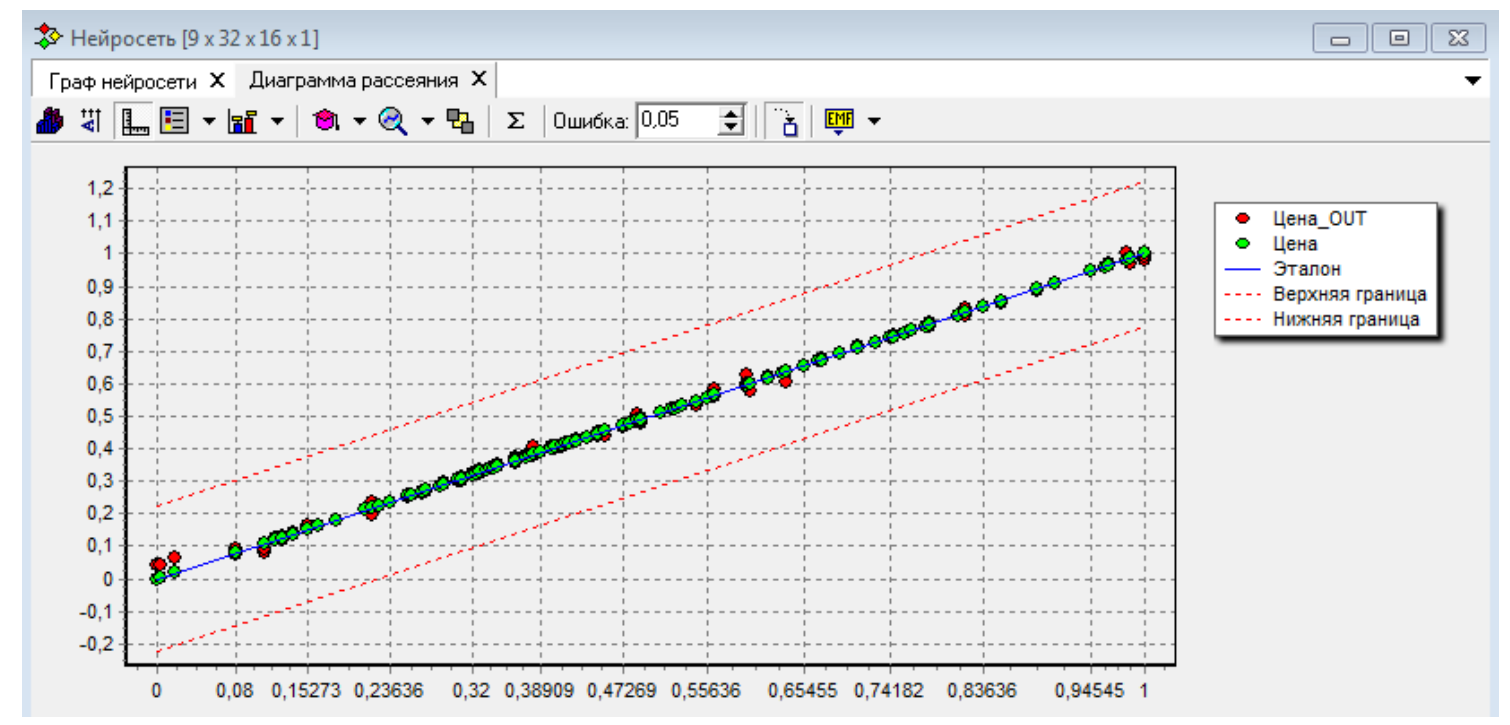

Рисунок 3 - Діаграма розсіювання після навчання.

\section{Висновки та напрямок подалыших досліджень.}

Таким чином, дослідженням підтверджено можливість використання нейронної мережі, а саме багатошарового персептрону, для оцінки ринкової вартості об'єктів житлової нерухомості на прикладі м. Маріуполь. Моделювання у середовищі Deductor Studio Academic дозволило обрати архітектуру нейронної мережі для подальшого використання. Використання методу оцінки ринкової вартості об'єктів житлової нерухомості на основі прогнозування 3 допомогою багатошарового персептрону дозволить підвищити ефективність процесу оцінки. Цей метод у подальшому планується впровадити у систему підтримки прийняття рішень для оцінювачів ріелтерської компанії. Впровадження методу на основі нейромережевих технологій дозволить автоматизувати процес пошуку закономірностей між об'єктами житлової нерухомості при різних параметрах та встановлювати об'єктивну ринкову вартість.

\section{Перелік використаних джерел}

1.Про внесення змін до Податков... | від 05.12.2019 № 354-IX https://zakon.rada.gov.ua/laws/show/354-20\#Text

2.Оцінити нерухомість можна буде онлайн | БІЗНЕС https://biz.ligazakon.net/ua/news/191492_otsniti-nerukhomst-mozhna-budeonlayn

3.До уваги суб'єктів оціночної діяльності та оцінювачів http://www.spfu.gov.ua/userfiles/files/do\%20uvagi\%20SOD.pdf

4.Оцінка та управління нерухомістю: навчальний посібник / В. Р. Кучеренко, М. А. Заєць, О. В. Захарченко, Н. В. Сментина, В. О. Улибіна. - Одеса: Видавництво ТОВ «Лерадрук», 2013. - 272 с.

5.Вся нерухомість України - Пошуковик нерухомості Flatfy від ЛУН https://flatfy.lun.ua/uk

6.Григорків В. С. Нейронні мережі та їхнє використання для прогнозування тенденцій ринку нерухомості / В. С. Григорків, О. І. Ярошенко, Н. В. Філіпчук // Науковий вісник НЛТУ України. - 2012. - Вип. 22.5. - С. 324-330. - Режим доступу: http://nbuv.gov.ua/UJRN/nvnltu_2012_22.

7.Алексеев А.О., Харитонов В.А., Ясницкий В.Л. Разработка концепции комплексного нейросетевого моделирования процессов массовой оценки и сценарного прогнозирования рыночной стоимости жилой недвижимости // Известия вузов. Инвестиции. Строительство. Недвижимость. 2018. №1 (24). URL: https://cyberleninka.ru/article/n/razrabotka-kontseptsiikompleksnogo-neyrosetevogo-modelirovaniya-protsessov-massovoy-otsenki-i-stsenarnogo-prognozirovaniya.

8.Кошель А. О. Використання нейромережевих технологій для проведення масової оцінки земель / А. О. Кошель // Формування ринкових відносин в Україні. - 2016. - № $12 . \quad$ - С. 77-81. - Режим доступу: http://nbuv.gov.ua/UJRN/frvu_2016_12_17.

9.Журавель О. Ю. Штучні нейронні мережі в оцінці вартості будівельних проектів / О. Ю. Журавель, Н. О. Вельмагіна // Строительство, материаловедение, машиностроение : сб. науч. тр. / Приднепр. гос. акад. стр-ва и архитектуры. - Днепр, 2018. - Вып. 106. - С. 52-57. - (Компьютерные системы и информационные технологии в образовании, науке и управлении). DOI: https://doi.org/10.30838/P.CMM.2415.270818.52.229

10. Евстафьев А. И., Гордиенко В. А. Прогнозирование индикаторов рынка недвижимости с применением нейронных сетей // Известия вузов. Северо-Кавказский регион. Серия: Общественные науки. $2009 . \quad$ №5. URL: https://cyberleninka.ru/article/n/prognozirovanie-indikatorov-rynka-nedvizhimosti-s-primeneniem-neyronnyh-setey.

11. Герасимов С. А. Моделирование нейронных сетей для оценки стоимости аренды объекта офисной недвижимости с наименьшей ошибкой // Горный информационно-аналитический бюллетень (научно-технический журнал), 2011. №12. URL: https://cyberleninka.ru/article/n/modelirovanie-neyronnyh-setey-dlya-otsenki-stoimosti-arendy-obekta-ofisnoy-nedvizhimosti-snaimenshey-oshibkoy. 
12. Воронін, В. О. Мамчин, М. М. Лянце, Е. В. Прогнозне моделювання тенденцій розвитку ринку нерухомості Логістика. 2012. - №735 [37] http://ena.lp.edu.ua:8080/bitstream/ntb/16008/1/7-Voronin-38-46.pdf

13. Тазетдінов В. А. Нейромережеве прогнозування ринку нерухомості у кризових умовах / В. А. Тазетдінов // Науковий вісник НЛТУ України. - 2015. - Вип. 25.2. - С. 344-350. - Режим доступу: http://nbuv.gov.ua/UJRN/nvnltu_2015_25.2_59

14. Арефьева Е. А., Костяев Д. С. Использование нейронных сетей для оценки рыночной стоимости недвижимости // Известия ТулГУ. Технические науки. 2017. №10. URL: https://cyberleninka.ru/article/n/ispolzovanie-neyronnyh-setey-dlya-otsenkirynochnoy-stoimosti-nedvizhimosti.

15. Вахрушев В.И., Курзаева Л.В., Дьяков В.А. Нейросетевое моделирование оценки рыночной стоимости недвижимости с использованием Deductor // Современная техника и технологии. 2016. № 11. Ч. 2 [Электронный pecypc]. URL: http://technology.snauka.ru/2016/11/11407

16. 1Sun, Y., 2019. Real Estate Evaluation Model Based on Genetic Algorithm Optimized Neural Network. Data Science Journal, 18(1), p.36. DOI: http://doi.org/10.5334/dsj-2019-036

17. Jiafei Niu and Peiqing Niu. 2019. An intelligent automatic valuation system for real estate based on machine learning. In Proceedings of the International Conference on Artificial Intelligence, Information Processing and Cloud Computing (AIIPCC '19). Association for Computing Machinery, New York, NY, USA, Article 12, 1-6. DOI: https://doi.org/10.1145/3371425.3371454

\section{References}

1. On amendments to the Tax ... | from 05.12.2019 № 354-IX https://zakon.rada.gov.ua/laws/show/354-20\#Text

2. You can evaluate the property online | BUSINESS https://biz.ligazakon.net/ua/news/191492_otsniti-nerukhomst-mozhna-budeonlayn

3. To the attention of subjects of appraisal activity and appraisers http://www.spfu.gov.ua/userfiles/files/do\%20uvagi\%20SOD.pdf

4. Estimation and management of real estate: a textbook/VR Kucherenko, MA Zayets, OV Zakharchenko, NV Smentina, VO Ulybina. - Odessa: Leradruk LLC Publishing House, 2013. - 272 p.

5. All real estate in Ukraine - Flatfy real estate search engine from LUN https://flatfy.lun.ua/en

6. Grigorkiv VS Neural networks and their use for forecasting real estate market trends / VS Grigorkiv, OI Yaroshenko, NV Filipchuk // Scientific Bulletin of NLTU of Ukraine. - 2012. - Vip. 22.5. - P. 324-330. - Access mode: http://nbuv.gov.ua/UJRN/nvnltu_2012_22. 7. Alekseev AO, Kharitonov VA, Yasnitsky VL Development of the concept of complex neural network modeling of processes of mass assessment and scenario forecasting of market value of residential real estate // Izvestiya vuzov. Investments. Construction. Real estate. 2018. №1 (24). URL: https://cyberleninka.ru/article/n/razrabotka-kontseptsii-kompleksnogo-neyrosetevogo-modelirovaniyaprotsessov-massovoy-otsenki-i-stsenarnogo-prognozirovaniya.

8. Koshel AA The use of neural network technologies for mass land valuation / AA Koshel // Formation of market relations in Ukraine. - 2016. - № 12. - P. 77-81. - Access mode: http://nbuv.gov.ua/UJRN/frvu_2016_12_17.

9. Zhuravel OY Artificial neural networks in the assessment of the cost of construction projects / OY Zhuravel, NO Velmagina // Construction, materials science, mechanical engineering: collection. scientific tr. / Приднепр. state acad. str-va and architecture. Dnipro, 2018. - Issue. 106. - P. 52-57. - (Computer systems and information technologies in education, science and management). DOI: https://doi.org/10.30838/P.CMM.2415.270818.52.229

10.Evstafiev AI, Gordienko VA Forecasting of real estate market indicators using neural networks // Izvestiya vuzov. North Cauca sus region. Series: Social Sciences. 2009. №5. URL: https://cyberleninka.ru/article/n/prognozirovanie-indikatorov-rynka-nedvizhimosti-sprimeneniem-neyronnyh-setey.

11.Gerasimov SA Modeling of neural networks to estimate the cost of renting an office property with the least error // Mining information and analytical bulletin (scientific and technical journal), 2011. №12. URL: https://cyberleninka.ru/article/n/modelirovanieneyronnyh-setey-dlya-otsenki-stoimosti-arendy-obekta-ofisnoy-nedvizhimosti-s-naimenshey-oshibkoy.

12.Voronin, VO Mamchin, MM Lyantse, EV Predictive modeling of real estate market trends Logistics. - 2012. - №735 [37] http://ena.lp.edu.ua:8080/bitstream/ntb/16008/1/7-Voronin-38-46.pdf

13.Tazetdinov VA Neural network forecasting of the real estate market in crisis conditions / VA Tazetdinov // Scientific Bulletin of NLTU of Ukraine. - 2015. - Vip. 25.2. - P. 344-350. - Access mode: http://nbuv.gov.ua/UJRN/nvnltu_2015_25.2_59

14.Arefieva EA, Kostyaev DS The use of neural networks to assess the market value of real estate // Izvestiya TulGU. Technical sciences. 2017. №10. URL: https://cyberleninka.ru/article/n/ispolzovanie-neyronnyh-setey-dlya-otsenki-rynochnoy-stoimostinedvizhimosti.

15.Vakhrushev VI, Kurzaeva LV, Dyakov VA Neural network modeling of real estate market valuation using Deductor // Modern equipment and technologies. 2016. № 11. Part 2 [Electronic resource]. URL: http://technology.snauka.ru/2016/11/11407

16.1Sun, Y., 2019. Real Estate Evaluation Model Based on Genetic Algorithm Optimized Neural Network. Data Science Journal, 18 (1), p.36. DOI: http://doi.org/10.5334/dsj-2019-036

17.Jiafei Niu and Peiqing Niu. 2019. An intelligent automatic valuation system for real estate based on machine learning. In Proceedings of the International Conference on Artificial Intelligence, Information Processing and Cloud Computing (AIIPCC '19). Association for Computing Machinery, New York, NY, USA, Article 12, 1-6. DOI: https://doi.org/10.1145/3371425.3371454 